\title{
A Review of Application of Affordance Theory in Information Systems
}

\author{
Huifen Wang, Jialu Wang, Qiuhong Tang \\ Department of Business Administration, Jinan University, Guangzhou, China \\ Email: 18761898508@163.com
}

How to cite this paper: Wang, H.F., Wang, J.L. and Tang, Q.H. (2018) A Review of Application of Affordance Theory in Information Systems. Journal of Service Science and Management, 11, 56-70. https://doi.org/10.4236/jssm.2018.111006

Received: December 20, 2017

Accepted: February 6, 2018

Published: February 9, 2018

Copyright ( 2018 by authors and Scientific Research Publishing Inc. This work is licensed under the Creative Commons Attribution International License (CC BY 4.0).

http://creativecommons.org/licenses/by/4.0/

(c) (i) Open Access

\begin{abstract}
This paper analyzes the status quo and tendency of the affordance theory in Information System literature, which can help us understand the relationship between technologies, users and organizations. This would pose a significant value on the related organizational changes and the use of social media. Based on the data from top journals, we reviewed 111 papers from Information Systems, Organization Studies and Management literatures on affordances according to the method of bibliometrics. From the analysis, we know that although the Information System discipline was a relatively late adopter, there is a large space to explore affordances in IS context. Based on the theoretical framework of affordances existence, perception, actualization and effects, we review the primary researches on affordances in IS discipline. In conclusion, IS scholars should focus on the affordance actualization, consider social affordances alongside technological affordances and improve our understanding of IT/IS-related organizational change and social media use in complicated social process.
\end{abstract}

\section{Keywords}

Affordances, Information System, Bibliometrics, Theoretical Framework

\section{Introduction}

Technology is closely connected with organization, affecting the structure of the organization and the direction of organizational development. The social cognition of the role of IS/IT has shifted from "production paradox" to "the greater investment of IS/IT, the better organization's overall performance". The theory of affordances, which was defined as "the possibilities for action", pioneered by the American ecological physiologist James J. Gibson [1], has attracted the attention of a large number of scholars in the fields of psychology, human-computer 
interaction and design. Recently, the affordance theory has gained large popularity among IS scholars in order to bring materiality back into our understanding of organizations [2]. These researchers are dedicated to studying the relationship and interactions between technical artifacts and organizations and to exploring how the physical properties of a tool or a technology provide different modes of interaction [3] [4] [5] [6] [7]. The affordance lens can help us understand the relationship between technology and the human actor. Researchers claim that affordances hold promise for a relational middle ground between technological determinism and social constructivism. In other words, affordance does not determine how people will use a technology, while at the same time technology's potential uses are not fully open-ended due to its materiality [8]. Although the Information System community was a relatively late adopter, there is a large space to explore affordances in IS context. The affordances concept has been used in the related organizational changes [4] [5] [7] and social media use [9].

This research could help us understand the status quo and tendency of the affordance theory in Information System literature. Since the definition and principles of affordances have enriched during the development, this paper integrates it so as to help us better understand the relationship between technologies, users and organizations. This would pose a significant value on the related organizational changes and the use of social media. The limitations of our review are as follows: 1) due to the large amount of relevant literature, we cannot summarize all the papers published, so, we just review the classic literatures of the top journals; 2) our review is mainly on technological affordances and ignores socialized affordances which are of great significance in future research.

In the next section, according to the methods of bibliometrics, we reviewed 111 articles from top journals in IS to understand the research status quo and tendency of the affordance theory in IS discipline. Then we formalize the concept of affordances as well as its origins and development. Subsequently, we draw on the theoretical framework of affordances in IS discipline from Pozzi et al. (2014) [10], which synthesizes our review and findings. Finally, we come to the conclusions of the review and offer the implications for future research and practice.

\section{Data Sources}

We limit the scope of our research to the field of information systems, organizational research and management. We selected papers with the key word "affordance(s)" published in the top journals such as MIS Quarterly, Journal of Information Technology and Organization Science as the source of our research. Until the first half of 2017, a total of 111 articles were obtained as academic samples for the study after deletion of non-related articles (see Table 1).

\section{Research Method}

\subsection{Bibliometrics}

Bibliometrics is a quantitative analysis method, which takes all kinds of external 
Table 1. Journals and quantities for analysis.

\begin{tabular}{lc}
\hline \multicolumn{1}{c}{ Journals } & Quantities \\
\hline MIS Quarterly & 8 \\
European Journal of Information Systems & 8 \\
Information Systems Research & 5 \\
Journal of Management Information Systems & 13 \\
Journal of the Association for Information Systems & 9 \\
Journal of Strategic Information Systems & 14 \\
Information Systems Journal & 14 \\
Journal of Information Technology & 13 \\
Organization Science & 17 \\
Information and Organization & 1 \\
Management Science & 111 \\
\hline Total & \\
\hline
\end{tabular}

characteristics of scientific literature as the research object and uses mathematical and statistical methods to describe, evaluate and predict the status quo and development trend of science and technology [11]. Researchers can use the thought of information philosophy, emphasizing the comprehensive application of bibliometrics and content analysis, so as to support the realization of transformation of data-information-knowledge-wisdom chain effectively. Using bibliometrics to study the geographical, periodical and institutional distribution of articles and finding the highly cited references can reveal the quantitative characteristics and variations of articles [12].

\subsection{Distributions According to Years}

Changes in the number of articles over time is one of the significant implications to measure the development trend of affordance theory in IS discipline (see Figure 1). Although the number of articles fluctuates during 12 years, the figure shows an upward trend with the maximum 23 in 2016. The IS discipline was a relatively late adopter compared to psychology or design due to the starting point 2005 but affordance theory has gradually received IS researchers' attention. From the stage of development, most literatures paid more attention to affordance existence and perception before 2013. Subsequently, IS scholars shifted the focus from affordance perception to actualization. After a certain period of bottleneck, the number of papers began to rise. From the figure, we can see the slope of each rising period is greater than or equal to the absolute value of the slope of the falling period, indicating that the development of each stage is firstly quantitatively expanded and then further developed to the depth to promote the continuous development of the research. 


\subsection{Distributions of Cited Citations}

The level of citations of academic papers reflects their influence and scope. We counted the cited citations of articles about affordance theory in IS literature on the SpiScholar platform (see Figure 2). From the picture, literature cited 0 - 10 times takes the largest proportion, most of which are published in the past three years while literature cited more than 200 times takes the least with many classic papers such as Zammuto (2007) cited 627 times and Leonardi (2011) cited 640 times, from which we can see their significant influences.

\section{Origins and Development of Affordance Theory}

The concept of affordances originates from the American ecological psychologist James J. Gibson who defined affordances as “action possibilities" [1] [4] [5] [9] [13] for animals in relation to the properties of a given environment. As he said in his book, "objects are composed of their qualities... color, texture, composition, size shape and features of shape, mass, elasticity, rigidity, and mobility...

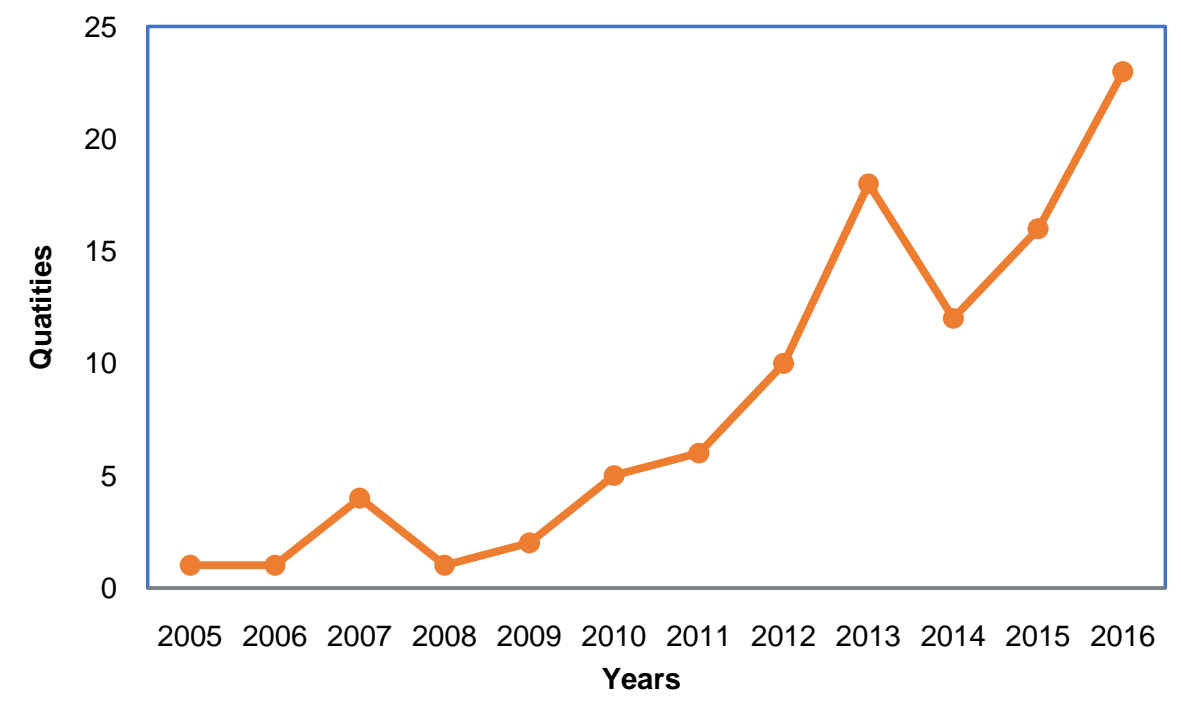

Figure 1. Changes in the number of articles over time.

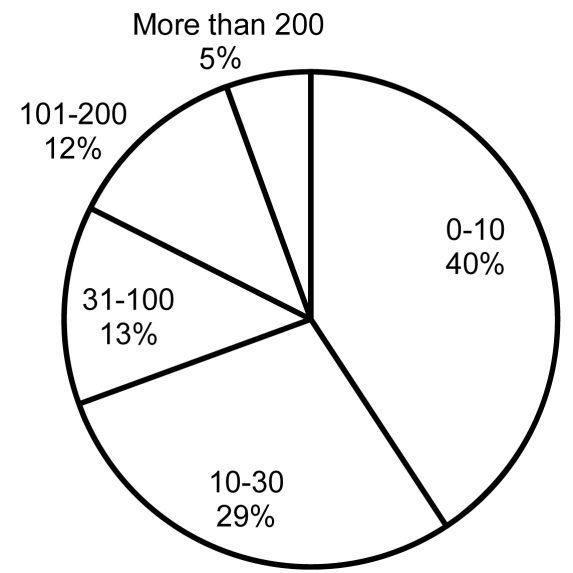

Figure 2. Distributions of cited citations. 
but I now suggest that what we perceive when we look at objects are their affordances, not their qualities" [14]. Cognitive and behavioral psychologists consider that perception is entirely the internal process of thought, while Gibson holds the opposite view. He believes that the environmental information is present in the environment and can be directly perceived, that is, affordances is related to animals but independent of animals' ability to recognize them. For example, a horizontal log provides people with the chance of sitting and can also be as a climbing stone, which depends on the goal of agency. However, the affordance of sitting exists whether the agency sits or not, which indicates that affordances exist independent of people's perception. Gibson's original definition of affordances is somewhat ambiguous about whether the affordances are properties of objects or of the relationship between objects and actors. After some debate, there was a common understanding among ecological psychologists that affordances, defined as possibilities for action, are properties of the relationship [5] [15] [16].

With the development of the affordance theory, it has gradually spread to the sociotechnical systems. It is Norman (1988), a cognitive psychologist from America, who applied Gibson's affordance theory to HCI (Human-Computer Interaction) and technology design. He defines affordances as "the perceived and actual properties of the thing, primarily those fundamental properties that determine just how the thing could possibly be used" [17]. In his opinion, users are important because they can perceive and understand the affordances of a design while they cannot create them because affordances are "designed-in" properties of objects, created by the designer intentionally. He distinguished affordances from perceived affordances and actual affordances. According to Norman, users are more concerned with the effect produced by the perceived affordances than actual affordances. Thus, a good design should make users easily perceive the designed affordances in case of any possible misunderstandings [2] [17]. Norman gave a door handle example that in our cognition, a thin and vertical door handle affords pulling, while a flat and horizontal door handle is used to push. However, a symmetrical door handle seems both can be used to pull or push the door, which is a bad design that can be misinterpreted or even unusable since the function (or the affordance) does not match the perception of users. Norman considers that affordances depend on users' abilities of action and their use background, while Gibson holds the opinion that "affordances do not change across different contexts of use" [6], which shows differences between them.

Hutchby is one of the first authors to apply the theory of affordances from the environment to technologies, considering affordances as the relationship between IT artifacts, people and organizations. According to Hutchby, affordances are not "exclusively properties of people or of artifacts" [16], they are embedded in relationships between users and the physical properties of artifacts with which they interact. Based on different goals and needs, people can achieve multiple outcomes through the perception of technologies and the use of materiality of artifacts. The relational thinking of Hutchby towards affordances holds a middle 
ground for the polarization of social constructivism (technology is a whiteboard that is only given meaning and structure through people's interpretations) and technological determinism (people's behaviors are determined by technology) [4]. That is to say, the existence of affordances is objective, it does not rely on the meaning and interpretation given by human beings while people are subjective, perceiving and actualizing affordances according to their own goals so as to produce different effects. It coincides with Boudreau and Robey's perspective that "technology is enacted from an evolving human agency, but may also constrain that agency" [18]. Affordances emerge from the relations between agencies and artifacts, reflecting the possibilities of action caused by the artifacts and related to the goals and capacities of actors.

Most of traditional viewpoints hold that technology is subjectively perceived as an objective result, and under the guidance of such a viewpoint, we can see many technical analyses fall into a dichotomy. As a result, People are either addicted to various transcendental philosophical conjectures about human consciousness or are trapped in trivial analysis of "things". Affordances provide a perspective of relational research that goes beyond the dichotomy between subject and object, which is not the individual part and individual phenomenon of things, but the relationship between things, which is to put things into an objective relationship so as to make the research object present a more comprehensive structure.

The definition and concept of affordances have been greatly refined and expanded through development. It is important to refine it further in order to successfully apply it to IS discipline, which focuses on filling the research gap between the theory of affordances and IS. Typical literatures on affordances in IS discipline have described that affordances are "possibilities for goal-oriented action afforded to specified user groups by technical objects" [3], emerging from the intersection (i.e. relationship) of IT artifacts and organizational features [4]. Some scholars think that affordances need to be "triggered" [5] or "actualized" [19] by actors in order to achieve different outcomes and effects since affordances only refer to possibilities for action. IS scholars hold different opinions on whether affordances need to be perceived by actors just like literatures presented in ecological psychology. In next section, we draw on the theoretical framework of affordances in IS discipline from Pozzi et al. (2014) work [10], which synthesizes our review and findings.

\section{Theoretical Framework of Affordances in IS Discipline}

Pozzi et al. organized the evolution of affordance theory in IS discipline and put forward the theoretical framework that was adapted from the model of affordance perception and actualization, originated from Bernhard et al. (2013) (see Figure 3)

As we can see from Figure 3, the model has four steps based on temporal-causal relationship between affordances existence, perception, actualization 


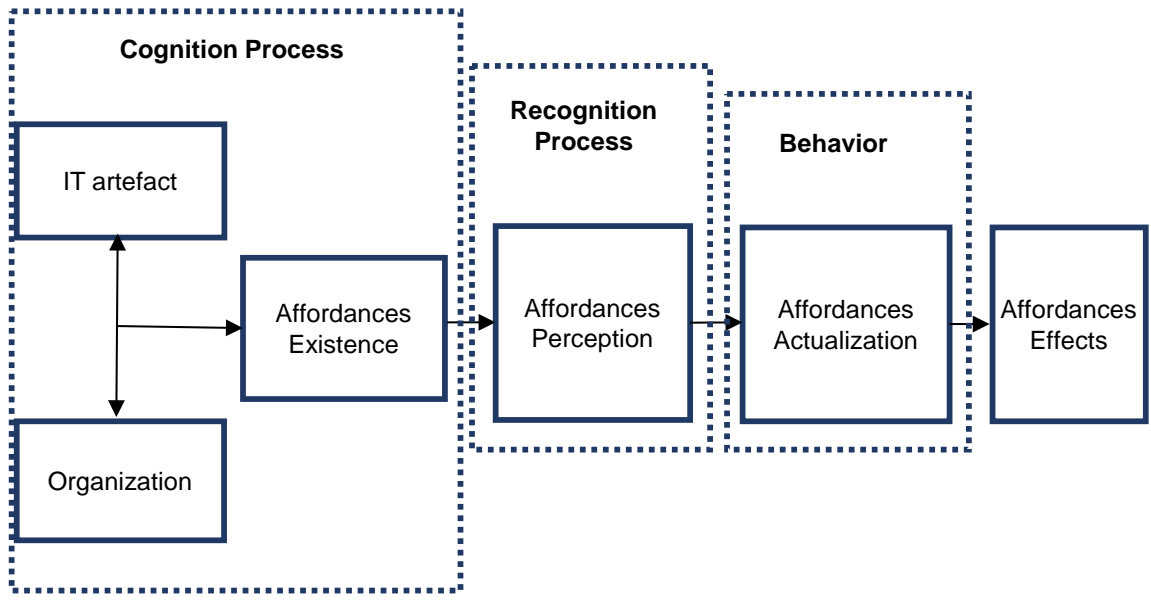

Figure 3. Theoretical framework of affordances in is discipline.

and effects. The first is the cognitive process of affordances existence, indicating that affordances exist from the interaction between IT artifacts and organization. The original model from Bernhard indicates that affordances exist from the relations between objects and users. When applying the theory of affordances to IS domain, researchers pay more attention to organizations consisting of groups, teams or business units rather than just users as individuals. Similarly, the objects refer to technologies or information systems such as Enterprise Resource Planning. The second is the recognition process, which means that the organization needs to perceive or recognize IT affordances. The third is the behavior, showing that the organization adopt the potentials for action which they perceive and actualize the IT affordances in support of organizational goals. Finally, this behavior will produce immediate concrete outcomes (i.e., effects in the long term).

\subsection{Affordance Existence}

It is a cognitive process [20] where users realize that there may be some potential for actions when they interact with objects. Affordances exist where IT artifact interacts with organization in IS space and are independent of people's perception. As can be seen from the arrow between IT artifact and organization, affordances are relational [4] [16]. They are not exclusively properties of the organization or of the IT artifact but the relationship and the result of the dynamic interaction between the two. Markus \& Silver (2008) are the first to propose the concept of functional affordances, defined as "the possibilities for goal-oriented action afforded to specified user groups by technical objects" [3]. This definition of functional affordances fully indicates the close relations between IT artifacts and users, and the relations are bi-directional. For example, a group decision support system is designed to adopt anonymous voting to find a solution that satisfies everyone for groups that want to reach agreement on decisions. However, it is difficult to achieve a consensus for a group under authoritarian leadership as it limits the opportunity of expression of different views. 
From the definition of functional affordances, we know affordances are related to actors' goals. Affordances which are consistent with our goals are of great significance to us and more likely to work, while those opposite to our goals are meaningless to us and may be ignored [15]. These analyses help us better understand how actors behave based on specific affordances and are meaningful for researches on applications of technologies.

An affordance is often seen as an enabler of action, but throughout the review, there is a set of notions of affordances and constraints, and some researchers think that affordances should include both the properties of enabling and constraining [5] [6] [7]. In the field of IS research, the set of matching concepts of affordances has a strong explanatory power because in the use of technology, there will inevitably enabling and constraining the possibility to act simultaneously. For example, firewall technology affords users behind firewalls the enabling affordance of security while at the same time providing constraining affordance of preventing unauthorized access by potential outsiders. This example shows that the organization recognizes and looks forward to the set of affordances in the implementation of firewall technology. However, the set of affordances might not be acceptable to the organization and would produce undesirable effects. For instance, the organization will choose to implement the ERP system so as to unify the business processes of the whole company. However, individual departments are greatly constrained in their ability in order to adapt to business process and standard, unified data flow system in operation. The example shows that the efficiency of individual departments will be greatly reduced in order to improve the efficiency of the entire organization. So it is very important for implementing information systems in specific environment to correctly understand the enable and constraint of affordances.

\subsection{Affordance Perception}

The perception of affordances is a process of recognition [21] of the affordance existence, which is influenced by the information that actors perceive about affordances. The symbolic expression of objects, defined as "the communicative possibilities of a technical object for a specified user group" [3], put forward by Markus \& Silver (2008), is one of the information that actors perceive and to make sure whether the affordance exists or not. The interface of an interactive software provides "message from designers to users about how users must interact with the system in order to achieve a certain range of goals and experience" [3]. The message (i.e., information) is not just limited to the interface itself, but may also come from other technical artifacts. Similarly, the information provided by the interface includes not only those that help users interact with IT artifacts, but also those are related to goals or values of designers or users [3]. That is to say, affordance perception is influenced by features of IT artifacts, which originate from intentions by designers, and by actors' capabilities and goal. The process of perception of affordances also fully demonstrates the relational prop- 
erty between IT artifacts and users.

Perceived affordances are different from affordances existence. When users perceive a part of existing affordances, the perceived affordances are a subset of existing affordances, while they can also be completely different sets when actors perceive wrong affordances because of lack of capacities or wrong understandings of the characteristics of objects.

The well-known designer, Gaver, held the opinion that affordances and perceptual information are two different concepts, the former is the possibilities of real actions and the latter is the messages of actions perceived by people [22]. In order to make the affordances of designs more perceptual in HCI, Gaver (1996) identified four categories of affordances based on affordances and existence of perceptual information: perceptible affordance (affordance and its information exist together), false affordance (information that users perceive belongs to an affordance that does not exist), hidden affordance (information of affordance does not exist and users need to recognize affordance by other means) and correctly rejected (both affordance and its information do not exist so users cannot perceive) [22]. The applications of affordances and perceptual information on design technologies emphasize the importance of creating perceived affordances. Although prior studies have shown the significance of affordances perception, scholars such as Volkoff \& Strong hold different opinions. Based on the principles of critical realism, they think affordances as generative mechanisms, rooted in real domain, do not need to be perceived [5]. They emphasize the importance of the process of affordances actualization.

\subsection{Affordance Actualization}

Recently more and more researchers have shown interest in affordance actualization process [5] [7] [13] [19] [23]. They think it is the process that ecological psychologists who first brought the concept of affordances ignored. A large number of prior studies on affordances in the field of ecological psychology held the opinion that actors can actualize the affordance easily, however, in contrast, recognizing affordances is only a first step for understanding organizational change in IS discipline. Individuals or groups in organizations may encounter various difficulties in the way to actualize affordances. It is critical to identify and thus solve the difficulties.

As is discussed before, Volkoff and Strong introduced IS affordances into the research perspective of generative mechanisms to understand the IT/IS-associated organizational change. They claim that affordances, as generative mechanisms, rooted in the "real" domain, do not need to be perceived [5]. According to the core principles of critical realism, they argue that affordances "arise in the real domain from the relation between the complex assemblages of organizations and IT artifacts", and are "actualized over time by organizational actors and lead to various effects we observe in the empirical domain" [5]. Combing the theory of affordances and critical realism to explain the difficulties faced by organization 
members in the implementation and use of information systems can help us improve our understanding of the IT-related organizational change and provide managers with thoughts and solutions to related issues.

It is Strong et al. who defined the concept of actualization clearly that it is "the actions taken by actors as they take advantage of one or more affordances through their use of technology to achieve immediate concrete outcomes in support of organizational goals" [19]. Actualization is a goal-oriented and iterative process [6] [7] [19]. The process of affordances actualization is presented in Figure 4. From the figure, we can know that goal-oriented actors interact with IT artifacts and take actions to actualize affordances to achieve immediate concrete outcomes in support of their goals, and these outcomes, in turn, provide feedback to adjust actions and those related to the actualized affordances [19].

The process of actualization of affordances was seen as an "individual journey". As is mentioned above, one of the research gaps that apply the affordance theory to IS discipline is understanding the differences between "individual level journey" and "organizational level journey". Based on the concept of collective constructs and the analysis of grounded theory of EHR system implementation, Strong et al. introduced the concept of actualization at an organizational level, seen as "the aggregation of many actors' actualization processes at an individual-level" [19]. Through the three methods, i.e. the "consistency", "extent", and "alignment" of individual actualization actions they proposed, "individual level journeys" can contribute to the "organizational level journey" and thus support organizational goals and lead to organizational level outcomes.

\subsection{Affordance Effect}

Through the process of affordances actualization, actors can achieve multiple effects observed in the "empirical" domain, according to the theory of critical realism. These effects are also called "immediate concrete outcome" [13] [19] in the

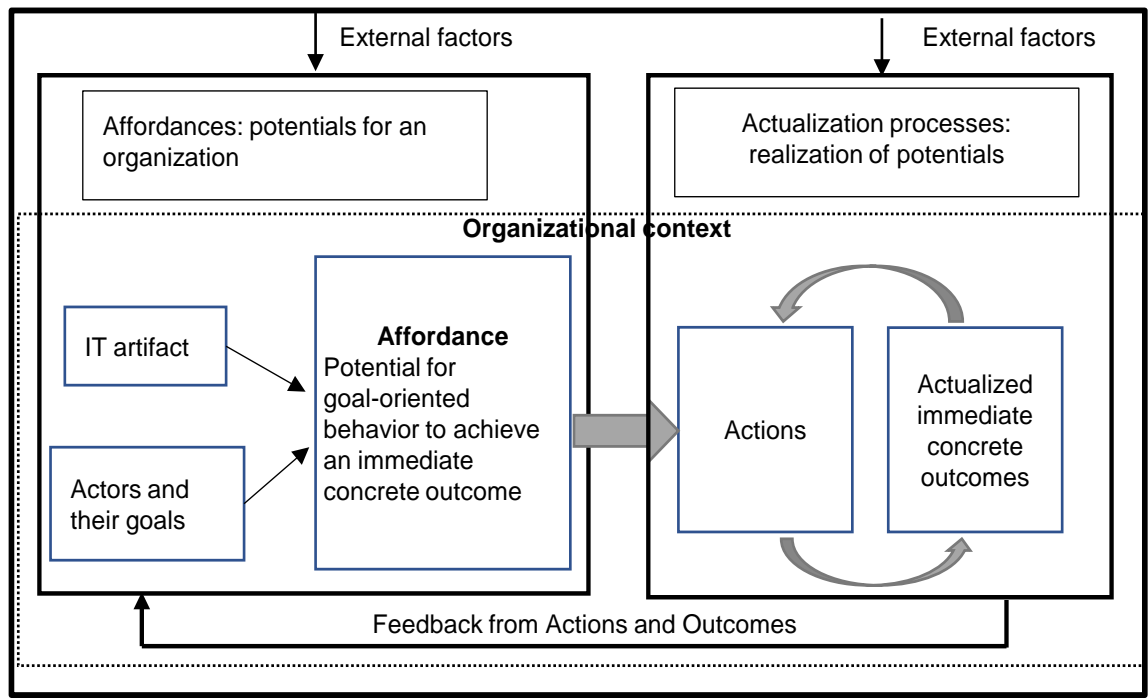

Figure 4. The process of affordance actualization. 
short term. An immediate concrete outcome refers to the result that can help us support the primary goals of organization. For example, an organization wants to improve the efficient use of resources (the primary organizational goals), it will install information systems like ERP in order to achieve this goal. Through the interaction between the organization and the IS, organizational members take actions to actualize the IS/IT affordances and achieve some immediate concrete outcomes such as standardization and coordination which can lead to the efficient use of resources i.e. effects in the long term. The concept of immediate concrete outcomes can help organizational members assess whether the process of actualizing affordances makes sense in achieving organizational goals [19].

As we mentioned above, some scholars in IS define affordances as "generative mechanism" [5] [13], which was described earlier as "one of the processes in a concrete system that makes it what it is" [24]. In the example of implementing ERP, the IS affordances refer to the potential for standardization and coordination, and the immediate outcomes are standardized business process and coordinated work environment. The concrete outcomes connect IT/IS affordances with organizational goals and make the information system what it is.

\subsection{Synthesis of the Literature Review}

Table 2 shows the primary researches on IS/IT affordances and on what part of the theoretical framework they focused.

\section{Conclusions}

We reviewed 111 articles from top journals in the field of information systems, organizational research and management to understand the research status quo and tendency of the affordance theory in IS discipline. According to the analysis of changes in the quantities of relevant articles over time and distributions of cited citations, we found that while the affordance theory is late in the field of information systems compared to psychology, design and other fields, its attention is dramatically increasing. Practical studies on affordances are on the rise, and the focus of research has gradually shifted from affordance itself to the influences and significance of IT artifacts to organizations and social actor intertwining.

We draw on the theoretical framework of affordances in IS discipline from Pozzi et al. (2014) work, which was adapted from the model of affordance perception and actualization, originated from Bernhard et al. (2013). The theoretical framework shows four steps based on temporal-causal relationship between affordances existence, perception, actualization and effects. Based on the framework, we review the primary researches on affordances in IS discipline.

We think that the definition of affordances in IS from Strong et al. is perfectly consistent with our review that affordances are "the potential for behaviors associated with achieving an immediate concrete outcome and arising from the relation between an artifact and a goal-oriented actor or actors" [19]. From the 
Table 2. Primary researches on IS/IT affordances.

\begin{tabular}{|c|c|c|c|c|c|c|}
\hline References & Research methods & Contributions to the understanding of affordances & A-Ex & A-P & A-A & A-Ef \\
\hline $\begin{array}{l}\text { Zammuto } \\
(2007)\end{array}$ & Theoretical analysis & $\begin{array}{l}\text { IT/IS has become a factor that cannot be ignored in organizational } \\
\text { change. } \\
\text { IT/IS affordances can affect the form and function of organizations, } \\
\text { and the evolving relationship between IT and organizations [4]. }\end{array}$ & $\checkmark$ & & & \\
\hline $\begin{array}{l}\text { Markus, Silver } \\
(2008)\end{array}$ & Theoretical analysis & $\begin{array}{l}\text { Properties of objects are important but insufficient to explain the } \\
\text { use and effects of objects. } \\
\text { Properties of objects can provide affordances-related information, } \\
\text { but affordances are not the properties of the objects. } \\
\text { Describing IT artifacts using two relational concepts, i.e. functional } \\
\text { affordances and symbolic expressions [3]. }\end{array}$ & $\checkmark$ & $\checkmark$ & & \\
\hline Leonardi (2011) & Single case analysis & $\begin{array}{l}\text { Technologies afford supporting or constraining during the process } \\
\text { of achieving organizational goals. } \\
\text { Based on the imbrications of human and material agencies, } \\
\text { members in organizations make decisions of changing routines } \\
\text { and technologies when they cannot achieve their goals [6]. }\end{array}$ & $\checkmark$ & & & \\
\hline Goh (2011) & Single case analysis & $\begin{array}{l}\text { The affordances of new systems will change the procedures and } \\
\text { routines of organizations. } \\
\text { Affordances evolve through actors' behavior [25]. }\end{array}$ & $\checkmark$ & $\checkmark$ & & \\
\hline $\begin{array}{l}\text { Volkoff, Strong } \\
\text { (2013) }\end{array}$ & Two cases analyses & $\begin{array}{l}\text { Affordances are generative mechanisms in organizational } \\
\text { change process, helping us improve our understanding of } \\
\text { IT-related changes [5]. }\end{array}$ & $\checkmark$ & & $\checkmark$ & $\checkmark$ \\
\hline Seidel (2013) & Single case analysis & $\begin{array}{l}\text { Socio-technical systems enable material properties of IS to create } \\
\text { functional affordances. } \\
\text { Building the theoretical framework of studying IS functional } \\
\text { affordances }[26] \text {. }\end{array}$ & $\checkmark$ & & & \\
\hline Robey (2013) & Theoretical analysis & $\begin{array}{l}\text { Uncovering the impact of materiality of IT on organizational } \\
\text { changes based on socio-technical perspective [27]. }\end{array}$ & $\checkmark$ & & & \\
\hline $\begin{array}{l}\text { Fayard, Weeks } \\
(2014)\end{array}$ & Literature review & $\begin{array}{l}\text { Interpreting affordances as both dispositional and relational. } \\
\text { Shifting the focus of affordance researches from the technology } \\
\text { to practice provided jointly by technology and organizing. } \\
\text { Offering the method of combining affordances with habitus to } \\
\text { explain practice based on sociomaterial perspectives [2]. }\end{array}$ & $\checkmark$ & & & \\
\hline Strong (2014) & Single case analysis & $\begin{array}{l}\text { Researches should address the indeterministic process of IT } \\
\text { artifacts and IT effects, the multilevel properties of IT-enabled } \\
\text { change and the intentional problems of actors. } \\
\text { Replacement of appropriation concept with actualization [19]. }\end{array}$ & $\checkmark$ & & $\checkmark$ & $\checkmark$ \\
\hline Grgecic (2015) & Empirical research & $\begin{array}{l}\text { Examining how IT-related factors influence the formation of } \\
\text { beliefs building on and extending the concept of functional } \\
\text { affordance and symbolic expression [28]. }\end{array}$ & $\checkmark$ & $\checkmark$ & & \\
\hline Bygstad (2016) & Single case analysis & $\begin{array}{l}\text { Drawing on the concept of affordances as an analytical construct } \\
\text { to identify and analyze mechanisms [13]. }\end{array}$ & $\checkmark$ & & $\checkmark$ & $\checkmark$ \\
\hline $\begin{array}{l}\text { Yingqin Zheng, } \\
\text { Ai Yu (2016) }\end{array}$ & Single case analysis & $\begin{array}{l}\text { Studying the socialized affordances of social media and adopting } \\
\text { the perspective of affordances-for-practice based on the theory of } \\
\text { collective action [9]. }\end{array}$ & $\checkmark$ & & & $\checkmark$ \\
\hline
\end{tabular}


definition and our review, we can reach the following conclusions: First, affordances are potentials for action. They are there, existing independent of people's perception or actualization; Second, affordances are relational. They are not "exclusively properties of people or of artifacts" [16], but rather embedded in relationships between users (i.e. actors) and the physical properties of objects (i.e. artifacts) with which they interact; Third, the perception or actualization of affordances depend on actors' goals and intentions. People are always inclined to actualize the potentials that are helpful to achieve their goals. In that sense, affordances include both the properties of enabling and constraining in that it will enable actions that are in line with the goals while constraining actions that are inconsistent with the goals.

In order to successfully apply the theory of affordances to IS discipline and explain IT uses and consequences, researchers must address two theoretical gaps: First, compared to the perception of affordances, researchers should pay more attention to the process of affordances actualization. More importantly, it is the factors (such as organizational structures and cultures) or difficulties (such as limited abilities and objections from members) they may encounter during the process that should receive attention rather than the process itself; Second, further attention on actualization process is needed at an organizational level. Several studies [29] show organizations manifest properties different from those of the sum of its groups or individuals. So organizational actualization of affordances should not been considered as just the sum of actors' actions.

Overall, the connotation of affordances has been greatly refined and expanded from applying the theory to IS/IT discipline to the concept of functional affordances put forward, and there have been some achievements in organizational change and use of social media. However, through the analysis and review of existing literature, we find that most of IS/IT affordances are put forward based on the property of materiality. It is insufficient in understanding the role of technology in organizational and societal transformation [9]. Leonardi (2011) indicated that due to the imbrications of human and material agencies, the operating procedures of organizations are closely linked to technologies that enable social interaction, and their consistency changes are also affected by the results of past imbrications. The current patterns are fundamentals of organizational changes in the future [6]. Fayard \& Weeks (2014) was an early attempt in the IS literature to adopt the perspective of affordances-for-practice, which means considering social affordances alongside technological affordances [2]. Y. Zheng \& A. Yu (2016) argued that affordances-for-practice arise from sociomaterial assemblages and embedded in complex, multi-dimensional and contested social, institutional and political processes [9]. Therefore, the concept of technological affordances needs "socializing" [30]. Affordances are more importantly about "actions in the world that involve technology", shaped by the social, institutional and historical environment in which they are situated [31]. Hence, when studying the affordance theory in IS field, scholars should pay attention to the materiality as well 
as the social aspects of affordances and shift the analytical focus from technology to practices.

\section{Fund Project}

National Natural Science Foundation of China: Research on the Mechanism of Online Symbolic Action to Consumer Drift (71761003).

\section{References}

[1] Gibson, J.J. (1977) The Theory of Affordances. Erlbaum Associates, Hillsdale, NJ.

[2] Fayard, A. and Weeks, J. (2014) Affordances for Practice. Information \& Organization, 24, 236-249. https://doi.org/10.1016/j.infoandorg.2014.10.001

[3] Markus, M.L. and Silver, M.S. (2008) A Foundation for the Study of IT Effects: A New Look at DeSanctis and Poole's Concepts of Structural Features and Spirit. Journal of the Association for Information Systems, 9, 609-632.

[4] Zammuto, R.F., Griffith, T.L., Majchrzak, A., Dougherty, D.J. and Faraj, S. (2007) Information Technology and the Changing Fabric of Organization. Organization Science, 18, 749-762. https://doi.org/10.1287/orsc.1070.0307

[5] Volkoff, O. and Strong, D.M. (2013) Critical Realism and Affordances: Theorizing IT-Associated Organizational Change Processes. MIS Quarterly, 37, 819-834. https://doi.org/10.25300/MISQ/2013/37.3.07

[6] Leonardi, P.M. (2011) When Flexible Routines Meet Flexible Technologies: Affordance, Constraint, and the Imbrication of Human and Material Agencies. MIS Quarterly, 35, 147-168. https://doi.org/10.2307/23043493

[7] Leonardi, P.M. (2013) When Does Technology Use Enable Network Change in Organizations? A Comparative Study of Feature Use and Shared Affordances. MIS Quarterly, 37, 749-775. https://doi.org/10.25300/MISQ/2013/37.3.04

[8] Stendal, K., Thapa, D. and Lanamäki, A. (2016) Analyzing the Concept of Affordances in Information Systems. 2016 49 th Hawaii International Conference on System Sciences (HICSS), IEEE, Koloa, HI, 5-8 January 2016, 5270-5277. https://doi.org/10.1109/HICSS.2016.651

[9] Zheng, Y. and Yu, A. (2016) Affordances of Social Media in Collective Action: The Case of Free Lunch for Children in China. Information Systems Journal, 26, 289-313. https://doi.org/10.1111/isj.12096

[10] Pozzi, G., Pigni, F. and Vitari, C. (2014) Affordance Theory in the IS Discipline: A Review and Synthesis of the Literature. Annalen Der Chemie Und Pharmacie, 2009, 1925-1933.

[11] Zhu, L. and Meng, X. (2013) A Comparative Study of Bibliometrics and Content Analysis. Library Work and Study, 6, 64-66.

[12] Zhang, J., Li, Q. and Zhao, D. (2017) Visualized Analysis of Research Status and Evolution of Information Elaboration-Based on Literatures Abroad. Information Studies. Theory \& Application, 2, 139-144.

[13] Bygstad, B., Munkvold, B.E. and Volkoff, O. (2016) Identifying Generative Mechanisms through Affordances: A Framework for Critical Realist Data Analysis. Journal of Information Technology (Palgrave Macmillan), 31, 83-96. https://doi.org/10.1057/jit.2015.13

[14] Gibson, J.J. (2014) The Ecological Approach to Visual Perception: Classic Edition. Psychology Press, Hove. 
[15] Stoffregen, T.A. (2003) Affordances as Properties of the Animal-Environment System. Ecological Psychology, 15, 115-134. https://doi.org/10.1207/S15326969ECO1502_2

[16] Hutchby, I. (2001) Technologies, Texts and Affordances. Sociology, 35, 441-456. https://doi.org/10.1177/S0038038501000219

[17] Norman, D.A. (1999) Affordance, Conventions, and Design. ACM, New York.

[18] Boudreau, M. and Robey, D. (2005) Enacting Integrated Information Technology: A Human Agency Perspective. Organization Science, 16, 3-18. https://doi.org/10.1287/orsc.1040.0103

[19] Strong, D.M., Volkoff, O., Johnson, S.A., Pelletier, L.R., Tulu, B., Bar-On, I., Trudel, J. and Garber, L. (2014) A Theory of Organization-EHR Affordance Actualization. Journal of the Association for Information Systems, 15, 53-85.

[20] Davern, M., Shaft, T. and Te'Eni, D. (2012) Cognition Matters: Enduring Questions in Cognitive IS Research. Journal of the Association for Information Systems, 13, 273-314.

[21] Greeno, J.G. (1994) Gibson's Affordances.

[22] Gaver, W.W. (1996) Situating Action II: Affordances for Interaction: The Social Is Material for Design. Ecological Psychology, 8, 111-129. https://doi.org/10.1207/s15326969eco0802_2

[23] Bernhard, E., Recker, J.C. and Burton-Jones, A. (2013) Understanding the Actualization of Affordances: A Study in the Process Modeling Context.

[24] Mario, B. (2004) How Does It Work? The Search for Explanatory Mechanisms. Philosophy of the Social Sciences, 34, 182-210. https://doi.org/10.1177/0048393103262550

[25] Goh, J.M., Gao, G. and Agarwal, R. (2011) Evolving Work Routines: Adaptive Routinization of Information Technology in Healthcare. Information Systems Research, 22, 565-585. https://doi.org/10.1287/isre.1110.0365

[26] Seidel, S., Recker, J. and Vom Brocke, J. (2013) Sensemaking and Sustainable Practicing: Functional Affordances of Information Systems in Green Transformations. MIS Quarterly, 37, 1275-1300. https://doi.org/10.25300/MISQ/2013/37.4.13

[27] Robey, D., Anderson, C. and Raymond, B. (2013) Information Technology, Materiality, and Organizational Change: A Professional Odyssey. Journal of the Association for Information Systems, 14, 379-398.

[28] Grgecic, D., Holten, R. and Rosenkranz, C. (2015) The Impact of Functional Affordances and Symbolic Expressions on the Formation of Beliefs. Journal of the Association for Information Systems, 16, 580-607.

[29] Capra, F. and Luisi, P.L. (2014) The Systems View of Life.

[30] Costall, A. (1995) Socializing Affordances. Theory \& Psychology, 5, 467-481. https://doi.org/10.1177/0959354395054001

[31] Faraj, S. and Azad, B. (2012) The Materiality of Technology: An Affordance Perspective. In: Leonardi, P.M., Nardi, B.A. and Kallinikos, J., Eds., Materiality and Organizing. Social Interaction in a Technological World, Oxford University Press, Oxford, 237-258. https://doi.org/10.1093/acprof:oso/9780199664054.003.0012 